\title{
Pengaruh Pendidikan Tentang Seksual Saat Kehamilan Terhadap Persepsi Ibu Hamil Di Polindes Kasih Ibu Desa Pucangan Kecamatan Palang
}

\section{Influence of Sexual Education during Pregnancy Against Pregnant Women's Perception in Polindes Kasih Ibu Desa Pucangan Kecamatan Palang}

\author{
Tiara Putri Ryandini ${ }^{1}$, Dyah Pitaloka ${ }^{2}$ \\ ${ }^{1,2}$ Institute of Health Science Nahdlatul Ulama Tuban \\ Email: tiara.putriryandini16@gmail.com
}

\begin{abstract}
ABSTRAK
Hubungan seksual saat kehamilan kini menjadi masalah yang utama bagi ibu hamil dan pasanganya. Salah satu penyebab penurunan aktivitas seksual adalah, kecemasan terjadinya keguguran, kecemasan pada janin, ketidaknyamanan, perubahan fisik yang terjadi sepanjang kehamilan, ketakutan akan pecahnya ketuban, kecemasan terinfeksi penyakit tertentu atau kelelahan. Dengan memberikan pendidikan tentang seksual saat kehamilan terhadap ibu hamil diharapkan mampu mengatasi permasalahan ini. Tujuan penelitian ini untuk mengetahui pengaruh pendidikan tentang seksual saat kehamilan terhadap persepsi ibu hamil.

Penelitian ini menggunakan desain pre eksperimen(one group pra post test design) yang diambil dengan Systematic Purposive sampling yang melibatkan 26 responden. Pengumpulan data menggunakan kuesioner. Data dianalisis dengan menggunakan uji Wilcoxon dengan tingkat signifikan $\alpha \leq 0,05$.

Hasil uji statistik Wilcoxon diperoleh $p$ value $=0,000(\alpha<0,05)$, dengan demikian $\mathrm{H}_{1}$ diterima yang artinya ada pengaruh pendidikan tentang seksual saat kehamilan terhadap persepsi ibu hamil.

Dari hasil penelitian ini didapatkan bahwa pendidikan kesehatan seksual dapat mempengaruhi persepsi ibu menjadi baik. Oleh sebab itu, pendidikan tentang seksualitas saat kehamilan perlu dilakukan, yang bertujuan untuk merubah persepsi buruk pada ibu hamil untuk melakukan hubungan seksual secara aman dan tidak beresiko.
\end{abstract}

\section{Kata Kunci: Pendidikan Seksual, Persepsi Ibu Hamil}

\begin{abstract}
Sexual intercourse during pregnancy is now a major problem for pregnant women and their partners. One of the causes of decreased sexual activity is, anxiety of miscarriage, anxiety to the fetus, discomfort, physical changes that occur during pregnancy, fear of rupture of membranes, anxiety infected with certain diseases or fatigue. By providing education about sexual during pregnancy to pregnant mother is expected to overcome this problem. The purpose of this study to determine the effect of education about sexual during pregnancy to the perception of pregnant women.
\end{abstract}


This study used pre experimental design (one group pre post test design) taken with Systematic Purposive sampling involving 26 respondents. Data collection using questionnaires. Data were analyzed by using Wilcoxon test with significant level $\alpha \leq 0,05$.

Wilcoxon statistical test results obtained p value $=0,000(\alpha<0.05)$, thus H1 accepted which means there is influence of education about sexual during pregnancy to perception of pregnant woman.

From the research result of this study found that sexual health education can affect the perception of the mother to be good. Therefore, education on sexuality during pregnancy needs to be done, which aims to change the bad perception of pregnant women to have safe and non-risk sexual intercourse.

\section{Keywords: Sexual Education, Perception of Pregnant Women}

\section{PENDAHULUAN}

Persepsi ibu hamil tentang hubungan seksual saat kehamilan kini menjadi masalah yang utama bagi ibu hamil dan pasanganya. Hal ini juga yang menjadi salah satu penyebab penurunan aktivitas seksual seperti, kecemasan terjadinya keguguran, kecemasan pada janin, ketidak nyamanan, perubahan fisik yang terjadi sepanjang kehamilan, ketakutan akan pecahnya ketuban, kecemasan terinfeksi penyakit tertentu atau kelelahan (Claire, Crystal dan Farine, 2011). Beberapa pendapat dikaitkan dengan persepsi ibu hamil ketika melakukan hubungan seksual saat hamil diantaranya; kontraksi setelah seks dapat menyebabkan keguguran dan kelahiran prematur, bayi tidak mendapat oksigen yang cukup selama orgasme dan berhubungan dengan kontraksi, seks selama masa kehamilan atau oral seks atau anal seks tidak diizinkan oleh agama atau kepercayaan tertentu, dan perilaku oral seks dapat menyebabkan emboli udara dan melukai ibu dan janin (Daniel, 2010).

Rendahnya pengetahuan ibu hamil tentang seks selama masa kehamilan berpengaruh pada hubungan seksual pasangan itu sendiri (Tino, 2009).

Di Indonesia pada tahun 2015, didapatkan jumlah Ibu hamil sebanyak 5.304.863 orang (Pusat Data dan Informasi, Kemenkes RI,2015). Provinsi Jawa Timur menduduki urutan ke dua (643.557) ibu hamil setelah Provinsi Jawa Barat (979.472) ibu hamil (Pusat Data dan Informasi, Kemenkes RI,2015). Di Kabupaten Tuban jumlah data yang di peroleh dari laporan PWS-KIA Kab. Tuban ibu hamil sebanyak 17.909 orang pada tahun 2016 (Dinkes kab. Tuban, 2016). Dari data Puskesmas Sumurgung didapatkan jumlah ibu hamil 599 dan di Desa Pucangan terdapat sebanyak 65 ibu hamil pada bulan november tahun 2016. Dari survey awal yang dilakukan oleh peneliti pada tanggal 21 desember 2016 sebanyak 8 dari 10 ibu hamil dari jumlah keseluruhan ibu hamil sebanyak 65 orang- di Desa Pucangan mengatakan takut melakukan hubungan seksual saat kehamilan. 5 ibu hamil tidak memahami sama sekali tentang seksual saat kehamilan, sedangkan 3 ibu hamil memahami tentang hubungan seksual saat kehamilan namun masih takut 
melakukan hubungan seksual saat kehamilan.

Persepsi merupakan suatu proses otomatis yang terjadi dengan sangat cepat dan kadang tidak disadari, di mana seseorang dapat mengenali stimulus yang diterimanya. Persepsi yang dimiliki dapat mempengaruhi tindakan seseorang. Jika dikaitkan dengan risiko, maka persepsi terhadap risiko merupakan proses dimana individu menginterpretasikan informasi mengenai risiko yang mereka peroleh (Notoatmodjo, 2005). Persepsi seseorang dipengaruhi oleh pengetahuan yang didapatkan dari pendidikan. Pendidikan seksual selama masa kehamilan penting dilakukan melihat banyaknya ketakutan dan perubahan yang terjadi pada kehamilan. Paritas adalah wanita

Oleh sebab itu, pendidikan tentang seksualitas saat kehamilan perlu dilakukan, yang bertujuan untuk merubah persepsi buruk pada ibu hamil untuk melakukan hubungan seksual secara aman dan tidak beresiko. Selain itu hubungan seksual saat kehamilan bukan sekedar aktivitas yang biasa tetapi bermanfaat sebagai persiapan bagi otot-otot panggul untuk menghadapi proses persalinan(Bobak, 2004). Untuk menangani masalah tersebut bisa diatasi dengan pemilihan posisi yang nyaman dalam melakukan hubungan seksual. Posisi mempunyai peranan penting ketika melakukan hubungan seksual pada kehamilan. Posisi berbaring miring (saling berhadapan atau membelakangi) seringkali merupakan posisi yang paling nyaman. Begitu pula posisi perempuan diatas, sehingga lebih bisa mengendalikan saat penetrasi, namun posisi berhubungan seks berubah dengan jumlah anak yang pernah dikandung dan dilahirkan. Hal ini berkaitan dengan pengalaman seseorang ibu hamil (Notoatmodjo, 2010). Selain itu pasangan juga perlu secara bebas membahas hubungan seksual mereka selama hamil. Jika pasangan yang tidak memahami perubahan fisiologis dan psikologis yang cepat selama hamil akan menjadi bingung dengan perilaku pasangannya. Dengan membicarakan perubahan yang dialami, pasangan dapat memberi dukungan satu sama lain dan dapat menguatkan keinginan berhubungan seksual. Dengan demikian pasangan dapat membantu mengantisipasi perubahan dan membantu dengan menegoisasi hambatan yang untuk memfasilitasi kepuasan pasangan satu sama lain (Bobak, 2004; Daniel, 2010).

seiring bertambahnya usia kehamilan (Murkoff, 2006).

Berdasarkan latar belakang diatas maka penulis ingin meneliti apakah ada "pengaruh pendidikan tentang seksual saat kehamilan terhadap persepsi ibu hamil di polindes Kasih Ibu desa Pucangan kecamatan Palang”.

\section{BAHAN DAN METODE}

Penelitian ini menggunakan rancangan penelitian praeksperimental (one group pra post test design). Ciri tipe penelitian ini adalah mengungkapkan hubungan sebab akibat dengan cara melibatkan satu kelompok subjek. Kelompok subjek diobservasi sebelum dilakukan intervensi, kemudian diobservasi lagi setelah intervensi. Penelitian ini dilakukan di Di Polindes Kasih Ibu Desa Pucangan Kecamatan Palang pada bulan April 2019.

Populasi dalam penelitian ini adalah seluruh ibu hamil di polindes 
kasih ibu Desa Pucangan - kecamatan Palang sebanyak 26 responden. Populasi tersebut lalu diambil sampel dengan teknik purposive sampling. Data diperoleh dengan memberikan kuesioner pre-test dan post-tes tentang bahaya narkoba.

Analisis data dilakukan dengan beberapa tahap yaitu editing, scoring, coding, tabulating, dan kemudian dianalisa dengan uji Wilcoxon menggunakan program SPSS dengan nilai $\alpha=0,05$. Berarti tingkat kemaknaan dalam penelitian ini adalah sebesar 0,05.Sedangkan tingkat akurasinya sebesar $\mathrm{p}=0,000$.

\section{HASIL PENELITIAN}

\section{Gambaran Umum Lokasi Penelitian \\ Polindes KASIH IBU Desa} Pucangan terletak di jalan Argopuro No.01 Pucangan-Palang-Tuban. Luas Desa Pucangan adalah 44.577 Ha. Jumlah penduduk 5100 jiwa dengan perincian penduduk laki-laki sebanyak 2500 jiwa dan perempuan sebanyak 2600 jiwa dengan jumlah 3 dusun, 1 dukuh, RT 19, RW 3 dan KK.

Berikut adalah karakteristik responden berdasarkan umur Ibu Hamil di Polindes Kasih Ibu Desa Pucangan tahun 2019 yang disajikan dalam tabel 5.1.

Tabel 5.1 Distribusi Frekuensi Responden Berdasarkan Umur di Polindes Kasih Ibu Desa Pucangan Kecamatan Palang Kabupaten Tuban.

\begin{tabular}{|c|c|c|c|}
\hline No & Umur & Frekuensi & Persentasi \\
\hline 1 & $<20$ Tahun & 2 & $7,7 \%$ \\
\hline 2 & $\begin{array}{l}20-35 \\
\text { Tahun }\end{array}$ & 23 & $88,5 \%$ \\
\hline 3 & $>35$ Tahun & 1 & $3,8 \%$ \\
\hline & Jumlah & 26 & $100 \%$ \\
\hline
\end{tabular}

Sumber: Data Primer Peneliti, Tahun 2019

Berikut tabel 5.1 diatas diperoleh data bahwa hampir seluruhnya responden berumur 20-35 tahun yaitu 23 orang $(88,5 \%)$.
Berikut adalah karakteristik responden berdasarkan Pendidikan Ibu Hamil di Polindes Kasih Ibu Desa Pucangan tahun 2019 yang disajikan dalam tabel 5.2.

Tabel 5.2 Distribusi Frekuensi Responden Berdasarkan Pendidikan di Polindes Kasih Ibu Desa Pucangan Kecamatan Palang Kabupaten Tuban.

\begin{tabular}{cccc}
\hline No & Pendidikan & Frekuensi & Persentasi \\
\hline 1 & SD & 10 & $38,5 \%$ \\
2 & SMP & 14 & $53,8 \%$ \\
3 & SMA & 2 & $7,7 \%$ \\
\hline & Jumlah & 26 & $100 \%$ \\
\hline
\end{tabular}

Sumber: Data Primer Peneliti, Tahun 2019

Berdasarkan tabel 5.2 diatas diperoleh data bahwa sebagian besar responden dengan pendidikan SMP yaitu 14 orang $(53,8 \%)$. 
Berikut adalah karakteristik responden berdasarkan Pekerjaan Ibu Hamil di Polindes Kasih Ibu Desa
Pucangan tahun 2019 yang disajikan dalam tabel 5 .

\begin{tabular}{cccc}
\hline No & Pekerjaan & Frekuensi & Persentasi \\
\hline 1 & IRT & 9 & $34,6 \%$ \\
2 & Tani & 3 & $11,5 \%$ \\
3 & Wiraswasta & 14 & $53,8 \%$ \\
\hline & Jumlah & 26 & $100 \%$ \\
\hline
\end{tabular}

Sumber: Data Primer Peneliti, Tahun 2019

Tabel 5.3 Distribusi Frekuensi Responden Berdasarkan Pekerjaan di Polindes Kasih Ibu Desa Pucangan Kecamatan Palang Kabupaten Tuban.

Berdasarkan tabel 5.3 diatas diperoleh data bahwa sebagian besar responden dengan pekerjaan wiraswasta yaitu 14 orang $(53,8 \%)$.

Berikut adalah karakteristik responden berdasarkan Usia Kehamilan Ibu Hamil di Polindes Kasih Ibu Desa Pucangan tahun 2019 yang disajikan dalam tabel 5.4

Tabel 5.4 Distribusi Frekuensi Responden Berdasarkan Usia Kehamilan di Polindes Kasih Ibu Desa Pucangan Kecamatan Palang Kabupaten Tuban.

\begin{tabular}{cccc}
\hline \multirow{2}{*}{ No } & Usia & Frekuensi & Persentasi \\
& Kehamilan & 7 & $26,9 \%$ \\
1 & Trimester I & 19 & $73,1 \%$ \\
\hline & Trimester III & 26 & $100 \%$ \\
\hline
\end{tabular}

Sumber: Data Primer Peneliti, Tahun 2019

Berdasarkan tabel 5.4 diatas diperoleh data bahwa sebagian besar responden memasuki usia kehamilan 28/>28 minggu yaitu 19 orang $(73,1 \%)$.
Berikut adalah karakteristik responden berdasarkan Riwayat Penyakit Ibu Hamil di Polindes Kasih Ibu Desa Pucangan tahun 2019 yang disajikan dalam tabel 5.5

Tabel 5.5 Distribusi Frekuensi Responden Berdasarkan Riwayat Penyakit di Polindes Kasih Ibu Desa Pucangan Kecamatan Palang Kabupaten Tuban.

\begin{tabular}{cccc}
\hline No & Riwayat & Frekuensi & Persentasi \\
\hline 1 & Penyakit & 3 & $11,5 \%$ \\
2 & Asphus & 2 & $7,7 \%$ \\
3 & Hipertensi & 1 & $3,8 \%$ \\
4 & Gastritis & 2 & $7,7 \%$ \\
5 & Tidak Ada & 18 & $69,2 \%$ \\
& Jumlah & 26 & $100 \%$ \\
\hline
\end{tabular}

Sumber: Data Primer Peneliti, Tahun 2019 
Berdasarkan tabel 5.5 diatas diperoleh data bahwa sebagian besar responden tidak ada riwayat penyakit yaitu 18 orang $(69,2 \%)$.

\begin{abstract}
Berikut adalah karakteristik responden berdasarkan Sumber Informasi Ibu Hamil di Polindes Kasih Ibu Desa Pucangan tahun 2019 yang disajikan dalam tabel 5.6
\end{abstract}

Tabel 5.6 Distribusi Frekuensi Responden Berdasarkan Sumber Informasi di Polindes Kasih Ibu Desa Pucangan Kecamatan Palang Kabupaten Tuban.

\begin{tabular}{|c|c|c|c|}
\hline No & Sumber Informasi & Frekuensi & Persentasi \\
\hline 1 & Bidan & 21 & $80,8 \%$ \\
\hline 2 & Tetangga/Kerabat & 3 & $11,5 \%$ \\
\hline 3 & $\begin{array}{c}\text { Internet/Media } \\
\text { Sosial }\end{array}$ & 2 & $7,7 \%$ \\
\hline & Jumlah & 26 & $100 \%$ \\
\hline
\end{tabular}

Sumber: Data Primer Peneliti, Tahun 2019

Berdasarkan tabel 5.6 diatas diperoleh data bahwa hampir seluruhnya responden mendapatkan informasi dari Bidan yaitu 21 orang $(80,8 \%)$.

\begin{abstract}
Berikut adalah karakteristik responden berdasarkan Jumlah Kehamilan Ibu Hamil di Polindes Kasih Ibu Desa Pucangan tahun 2019 yang disajikan dalam tabel 5.7.
\end{abstract}

Tabel 5.7 Distribusi Frekuensi Responden Berdasarkan Jumlah Kehamilan di Polindes Kasih Ibu Desa Pucangan Kecamatan Palang Kabupaten Tuban.

\begin{tabular}{cccc}
\hline No & $\begin{array}{c}\text { Jumlah } \\
\text { Kehamilan }\end{array}$ & Frekuensi & Persentasi \\
\hline 1 & $\begin{array}{c}\text { Kehamilan } \\
\text { ke } 1\end{array}$ & 16 & $61,5 \%$ \\
2 & $\begin{array}{c}\text { Kehamilan } \\
\text { ke 2 } \\
\text { Kehamilan } \\
\text { ke }>2\end{array}$ & 9 & $34,6 \%$ \\
& Jumlah & 1 & $3,8 \%$ \\
\hline
\end{tabular}

Sumber: Data Primer Peneliti, Tahun 2019

Berdasarkan tabel 5.7 diatas diperoleh data bahwa sebagian besar responden memasuki kehamilan ke 1 yaitu 16 orang $(61,5 \%)$.
Berikut adalah karakteristik responden berdasarkan Jumlah Persalinan Ibu Hamil di Polindes Kasih Ibu Desa Pucangan tahun 2019 yang disajikan dalam tabel 5.8. 
Tabel 5.8 Distribusi Frekuensi Responden Berdasarkan Jumlah Persalinan di Polindes Kasih Ibu Desa Pucangan Kecamatan Palang Kabupaten Tuban.

\begin{tabular}{cccc}
\hline No & $\begin{array}{c}\text { Jumlah } \\
\text { Persalinan }\end{array}$ & Frekuensi & Persentasi \\
\hline 1 & Belum & 18 & $69,2 \%$ \\
2 & pernah & 7 & $26,9 \%$ \\
3 & Persalinan 1 & 1 & $3,8 \%$ \\
& Jumlah & 26 & $100 \%$ \\
\hline
\end{tabular}

Sumber: Data Primer Peneliti, Tahun 2019

Berdasarkan tabel 5.8 diatas diperoleh data bahwa sebagian besar responden belum pernah melakukan persalinan yaitu 18 orang $(69,2 \%)$.
Berikut adalah karakteristik responden berdasarkan Jumlah Abortus Ibu Hamil di Polindes Kasih Ibu Desa Pucangan tahun 2019 yang disajikan dalam tabel 5.9.

Tabel 5.9 Distribusi Frekuensi Responden Berdasarkan Jumlah Abortus di Polindes Kasih Ibu Desa Pucangan Kecamatan Palang Kabupaten Tuban.

\begin{tabular}{|c|c|c|c|}
\hline No & $\begin{array}{l}\text { Jumlah } \\
\text { Abortus }\end{array}$ & Frekuensi & Persentasi \\
\hline 1 & $\begin{array}{c}\text { Tidak } \\
\text { Pernah }\end{array}$ & 24 & $92,3 \%$ \\
\hline \multirow[t]{2}{*}{2} & 1 kali & 2 & $7,7 \%$ \\
\hline & Jumlah & 26 & $100 \%$ \\
\hline
\end{tabular}

Sumber: Data Primer Peneliti, Tahun 2019

Berdasarkan tabel 5.9 diatas diperoleh data bahwa hampir seluruhnya responden tidak pernah mengalami abortus yaitu 24 orang $(92,3 \%)$.

Berikut adalah persepsi Ibu hamil tentang seksual saat kehamilan sebelum diberikan pendidikan seksual saat kehamilan di Polindes Kasih Ibu Desa Pucangan Kecamatan Palang - Kabupaten Tuban yang disajikan dalam tabel 5.10 .

Tabel 5.10 Distribusi Frekuensi Persepsi Ibu hamil tentang seksual saat kehamilan sebelum diberikan pendidikan seksual saat kehamilan di Polindes Kasih Ibu Desa Pucangan - Kecamatan Palang - Kabupaten Tuban.

\begin{tabular}{cccc}
\hline \multirow{2}{*}{ No } & $\begin{array}{c}\text { Persepsi Ibu hamil tentang } \\
\text { seksual saat kehamilan }\end{array}$ & Frekuensi & Persentasi (\%) \\
\hline 1. & Baik & 1 & 3,8 \\
2. & Cukup & 11 & 42,3 \\
3. & Kurang & 14 & 53,8 \\
& & 26 & 100 \\
\hline
\end{tabular}

Dari tabel 5.10 diatas diperoleh data bahwa sebelum diberikan pendidikan seksual saat kehamilan sebagian besar responden memiliki 
persepsi kurang yaitu 14 orang $(53,8 \%)$.

Berikut adalah persepsi Ibu hamil tentang seksual saat kehamilan setelah diberikan pendidikan seksual saat kehamilan di Polindes Kasih Ibu Desa Pucangan - Kecamatan Palang - Kabupaten Tuban yang disajikan dalam tabel 5.11.

Tabel 5.11 Distribusi Frekuensi Persepsi Ibu hamil tentang seksual saat kehamilan setelah diberikan pendidikan seksual saat kehamilan di Polindes Kasih Ibu Desa Pucangan - Kecamatan Palang - Kabupaten Tuban.

\begin{tabular}{clccc}
\hline No & Persepsi Ibu hamil tentang seksual saat & Frekuensi & Persentasi (\%) \\
\hline 1. & Baik & & 9 & 34,6 \\
2. & Cukup & 15 & 57,7 \\
3. & Kurang & 2 & 7,7 \\
& & Jumlah & 26 & 100 \\
\hline
\end{tabular}

Sumber: Data Primer Peneliti, Tahun 2019

Dari tabel 5.11 diperoleh data bahwa setelah diberikan pendidikan seksual saat kehamilan sebagian besar responden memiliki persepsi cukup yaitu 15 responden $(57,7 \%)$.
Berikut adalah Pengaruh Pendidikan Tentang Seksual Selama Kehamilan terhadap Persepsi Ibu Hamil di Polindes Kasih Ibu Desa Pucangan - Kec. Palang

Tabel 5.12 Pengaruh Pendidikan Tentang Seksual Selama Kehamilan terhadap Persepsi Ibu Hamil di Polindes Kasih Ibu Desa Pucangan - Kec. Palang.

\begin{tabular}{llcccc}
\hline \multirow{2}{*}{ NO } & \multicolumn{1}{c}{$\begin{array}{c}\text { Pendidikan } \\
\text { Kesehatan }\end{array}$} & Baik & Cukup & Kurang & Total \\
\cline { 3 - 5 } 1. & $\begin{array}{l}\text { Sebelum diberikan } \\
\text { (Pre test) }\end{array}$ & 1 & 11 & 14 & 26 \\
& & $(3,8 \%)$ & $(42,3 \%)$ & $(53,8 \%)$ & $(100 \%)$ \\
2. & $\begin{array}{l}\text { Setelah diberikan } \\
\text { (Post test) }\end{array}$ & 9 & 15 & 2 & 26 \\
& & $(34,6 \%)$ & $(57,7 \%)$ & $(7,7 \%)$ & $(100 \%)$ \\
\hline
\end{tabular}

Sumber: Data Primer Peneliti, Tahun 2019

Berdasarkan tabel 5.12 di atas analisa dalam penelitian ini dilihat bahwa sebelum diberikan pendidikan kesehatan sebagian besar responden memiliki persepsi kurang sebanyak 14 orang $(53,8 \%)$, sedangkan setelah diberikan pendidikan kesehatan sebagian besar responden memiliki persepsi cukup sebanyak 15 orang $(57,7 \%)$.
Dari hasil penelitian yang di lakukan peneliti menunjukan bahwa ada pengaruh pendidikan seksual saat kehamilan terhadap persepsi ibu hamil di Polindes Kasih Ibu Desa Pucangan Kecamatan Palang tahun 2019. Hasil uji statistika diperoleh nilai Asymp. Sig. (2-tailed) $=0,000$ dimana $0,000<0,05$, maka $\mathrm{H}_{1}$ diterima $\mathrm{H}_{0}$ ditolak, yang artinya ada pengaruh pendidikan tentang seksual 
saat kehamilan terhadap persepsi ibu hamil di polindes kasih ibu Desa Pucangan Kecamatan Palang.

Dari tabel 5.11 dapat diketahui bahwa sebagian besar responden memiliki persepsi cukup. Adanya perubahan yang signifikan tersebut menunjukkan bahwa pendidikan seksual saat kehamilan memberikan dampak bagi ibu hamil yang masih memiliki persepsi yang kurang. Persepsi merupakan suatu proses otomatis yang terjadi dengan sangat cepat dan kadang tidak disadari, di mana seseorang dapat mengenali stimulus yang diterimanya. Persepsi yang dimiliki dapat mempengaruhi tindakan seseorang. Jika dikaitkan dengan risiko, maka persepsi terhadap risiko merupakan proses dimana individu menginterpretasikan informasi mengenai risiko yang mereka peroleh (Notoatmodjo, 2005). Persepsi seseorang dipengaruhi oleh pengetahuan yang didapatkan dari pendidikan. Pendidikan seksual selama masa kehamilan penting dilakukan melihat banyaknya ketakutan dan perubahan yang terjadi pada kehamilan. Paritas adalah wanita dengan jumlah anak yang pernah dikandung dan dilahirkan. Hal ini berkaitan dengan pengalaman seseorang ibu hamil (Notoatmodjo, 2010).

Berdasarkan tabel 5.12 di atas analisa dalam penelitian ini dilihat bahwa sebelum diberikan pendidikan kesehatan sebagian besar responden memiliki persepsi kurang, sedangkan setelah diberikan pendidikan kesehatan sebagian besar responden memiliki persepsi cukup. Dari data yang diperoleh peneliti bahwa hampir seluruhnya memiliki perubahan persepsi yang lebih baik setelah diberikan pendidikan kesehatan, sedangkan sebagian kecil memiliki persepsi tetap setelah diberikan pendidikan kesehatan (terlampir). Sehingga dapat dikatakan sampel penelitian ini mengalami perubahan antara sebelum (pre test) dan setelah (post test) diberi perlakuan berupa pendidikan kesehatan reproduksi Oleh sebab itu, pendidikan tentang seksualitas saat kehamilan perlu dilakukan, yang bertujuan untuk merubah persepsi buruk pada ibu hamil untuk melakukan hubungan seksual secara aman dan tidak beresiko.

Selain itu hubungan seksual saat kehamilan bukan sekedar aktivitas yang biasa tetapi bermanfaat sebagai persiapan bagi otot-otot panggul untuk menghadapi proses persalinan(Bobak, 2004). Untuk menangani masalah tersebut bisa diatasi dengan pemilihan posisi yang nyaman dalam melakukan hubungan seksual (Murkoff, 2006).

\section{KESIMPULAN}

Dari penelitian ini dapat disimpulkan bahwa :

1. Persepsi Ibu hamil tentang seksual saat kehamilan sebelum diberikan pendidikan seksual saat kehamilan di Polindes Kasih Ibu Desa Pucangan - Kecamatan Palang Kabupaten Tuban memiliki persepsi kurang.

2. Persepsi Ibu hamil tentang seksual saat kehamilan setelah diberikan pendidikan seksual saat kehamilan di Polindes Kasih Ibu Desa Pucangan - Kecamatan Palang Kabupaten Tuban memiliki persepsi cukup.

3. Terdapat pengaruh Pendidikan Tentang Seksual Selama Kehamilan dengan Persepsi Ibu Hamil di Polindes Kasih Ibu Desa Pucangan - Kec. Palang, ditunjukkan dengan hasil 0,000. 


\section{SARAN}

\section{Saran Teoritis}

Setelah mengetahui pengaruh pendidikan tentang seksual saat kehamilan terhadap persepsi ibu hamil, peneliti dapat mengetahui faktor-faktor kegagalan dan keberhasilan dalam pemberian pendidikan tentang seksual saat kehamilan terhadap persepsi ibu hamil.

2. Saran Praktis

1) Hasil penelitian ini dapat dijadikan untuk pengembangan mengenai intervensi hubungan seksual saat kehamilan. Bagi institusi pendidikan agar terus dapat memperbanyak sumber bacaan baik buku, jurnal, maupun literatur lainnya mengenai keperawatan khususnya yang berhubugan dengan hubungan seksual saat kehamilan.

2) Diharapkan hasil penelitian ini dapat menjadi acuan untuk ibu hamil yang bertujuan untuk merubah persepsi buruk pada ibu hamil untuk melakukan hubungan seksual secara aman dan tidak beresiko.

\section{DAFTAR PUSTAKA}

Kementrian Kesehatan RI. Sekretariat Jenderal 2015. Profil Kesehatan Indonesia Tahun 2015. Jakarta : Kementerian Kesehatan RI. 2016.

Arikunto, S. 2006. Prosedur Penelitian Suatu Pendekatan Praktek. Jakarta: Rineka Cipta.

Fitri Farhani. 2014.Hubungan Tingkat Pendidikan Dengan Pengetahuan Ibu Hamil
Tentang Hubungan Seksual Saat Kehamilan Di Wilayah Sukabumi Utara, (online), (http://repository.uinjkt.ac.id/ dspace/bitstream/123456789/ 25545/1/FITRI\%20FARHAN I\%20-\%20fkik.pdf). di akses 2015.

Bobak, I.M., Lowdermilk, D.L., \& Jensen, M.D. 2004. Buku Ajar keperawatan Maternitas. Ed. 4. Jakarta: EGC.

Sagiv M, Dafna-Reiss., Birnbaum, Gurit E., Safir, Marilyn P,. 2012. Changes in Sexual Experience and Relationship Quality During Pregnancy. Arch Sex Behav, 41, 12411251.

Wijaya, Andik. 2004. 55 masalah seksual yang ingin anda ketahui tapi "tabu" untuk ditanyakan. Gramedia Pustaka Utama: Jakarta

\section{A Health Handbook For Women With} Disabilities. 2007. Diunduh dari www.hesperian.orgpada tanggal 7 November 2013 pukul 17.39

Cedli, Lussi Giovani. 2012. Fungsi Seksual Suami Selama Masa Kehamilan Pasangan. Skripsi Universitas Indonesia Fakultas Ilmu Keperawatan.

Winkjosastro, H., et al. 2002. Ilmu kebidanan. Jakarta: Yayasan Bina Pustaka Sarwono Prawiroharjo

Shojaa, Mahdie., Jouybari, Leila., \& Sanagoo, Akram. 2008. The sexual activity during 
pregnancy among a group of iranian women. Arch Gynecol Obstet, 279, 353-356.

Tino, A Rafi. 2009. Menjawab Mitosmitos Kehamilan dan Menyusui. Yogyakarta: Media Pressindo.

Glaiser Anna., \& Gebbie Alisa. Keluarga Berencana \& dan Kesehaan Reproduksi. Edisi 4. Jakarta: EGC.

Pangkahila, Wimpie. 2001. Seks Yang Membahagiakan:

Menciptakan Keharmonisan Suami Istri. Jakarta: Kompas.

Notoatmodjo,S. 2003. Metodologi Penelitian Keperawatan. Jakarta : Rineka Cipta.

Widyastuti, Y. 2009. Kesehatan Reproduksi. Yogyakarta : Fitramaya.

Admin, 2008. Kesehatan Reproduksi.

http://www.kespro.info.

Diakses tanggal 26 Desember 2013.

Budiarti, Astrida. 2010. Studi Fenomenologi: Pengalaman Seksualitas Perempuan Selama Masa Kehamilan di Surabaya. Tesis Fakultas IlmuKeperawatan Program Magister Keperawatan.

Wijaya, Andik. 2004. 55 masalah seksual yang ingin anda ketahui tapi "tabu" untuk ditanyakan. Gramedia Pustaka Utama: Jakarta.

Kuswandani, Ana Budi. 2011. MAYO CLINIC: Kehamilan yang Sehat. Jakarta: PT. Mitra Media Publisher.

Murkoff, Heidi. 2006. Kehamilan apa yang anda hadapi bulan per bulan. Ed.3. Jakarta: ARCAN.

Siswosuharjo, Suwignyo. 2010. Panduan Super Lengkap Hamil Sehat. Cet. 1. Jakarta: Penebar Plus.

Lee, Jian Tao et al., 2010. Sexual Positions and Sexual Satisfaction of Pregnant Women. Journal of Sex \& Marital Therapy, 36, 408420.

Carrol, Janell L. 2007. Sexuality Now: Embracing Diversity. Thomson.

Sacomori \& Cardoso. 2010. Sexual Initiative and Intercourse Behavior During Pregnancy Among Brazilian. Journal of Sex \& Marital Therapy, 36, 124-136.

Kissanti, Annia. 2007. 9 Bulan Penuh Keajaiban. Jakarta: Araska

Robbins 2003. Konsep Dasar Persepsihttp://repository.usu. ac.id/bitstream/123456789/34 764/4/Chapter\%20II.pdf. 